\title{
Prediction of Properties and Modeling Fire Behavior of Polyethylene using Cone Calorimeter
}

\author{
Roshan J. Patel and Qingsheng Wang* \\ Department of Fire Protection \& Safety and Department of Chemical Engineering, \\ Oklahoma State University, Stillwater, OK 74078, USA
}

* Corresponding author. Tel.: +1 405744 5508; fax: +1 405744 6758. E-mail addresses: qingsheng.wang@okstate.edu (Q. Wang).

\begin{abstract}
Fire behavior of pure polyethylene has been investigated by performing flammability analysis using a standard cone calorimeter. Specifications of polyethylene samples were $100 \pm 1 \mathrm{~mm}$ long, $100 \pm 1 \mathrm{~mm}$ wide and $5 \mathrm{~mm}$ thick, with mass of $25.0 \pm 0.1 \mathrm{gm}$. Sample surface area exposed to the external heat flux was limited to $94 \mathrm{~mm}$ in length, $94 \mathrm{~mm}$ in width due to use of edge lip sample holder frame. The values of external heat flux used were ranging from $40-55$ $\mathrm{kW} \cdot \mathrm{m}^{-2}$ with an incremental step of $5 \mathrm{~kW} \cdot \mathrm{m}^{-2}$. Three set of experiments were performed for each value of external heat flux. The results obtained were recorded and fitted to a set of mathematical equations to determine the thermal inertia, critical heat flux and the peak heat release rate. Study shows that thermal inertia value obtained from experimental data was $0.86 \mathrm{~kJ} \cdot \mathrm{m}^{-4} \cdot \mathrm{K}^{-2} \cdot \mathrm{s}^{-1}$ and from well-known correlations was $0.83 \mathrm{~kJ}^{2} \cdot \mathrm{m}^{-4} \cdot \mathrm{K}^{-2} \cdot \mathrm{s}^{-1}$ with a difference of $3.49 \%$. The factors to relate the observed critical heat flux with the actual critical heat flux were determined as 0.77 and 0.64 . The peak heat release rate for each test was determined using the model equation based on oxygen depletion index and concentrations of gaseous species such as oxygen, carbon monoxide, carbon dioxide and water. The values observed experimentally and the ones calculated had a standard deviation of $\pm 4.56 \%$. Thus, this work serves as basis for transformation of qualitative understanding of polyethylene fire behavior into systematic quantification, which can be generalized for other polymers and their composites.
\end{abstract}

Keywords: cone calorimeter; modeling; polyethylene; heat release rate; thermal inertia; critical heat flux 


\section{Introduction}

It is observed that construction and manufacturing industries are favoring polymers over other materials due to their machinability, raw material cost, easy processing, availability and their structural \& chemical stability. Apart from these attractive properties, their easy availability and a reliable supply at competitive prices are constantly out casting the conventional materials. This has resulted in transition with steady increase in the share of polymers in manufacturing industry. In the times when polymers are being accepted as a feasible and reliable replacement we also have to be cautious about the risks associated with them, specifically fire hazard. As we all know most of the conventional polymers are based on hydrocarbon backbone, which pose a fire hazard. Thus it is of prime importance to understand the fire behavior of polymers.

Efforts are ongoing to study the fire behavior of the polymers and their nanocomposites as promising flame retardants (Wang, 2013). Fire behavior of black polymethyl methacrylate (PMMA) was studied and its property characterization has been demonstrated (Luche et al., 2001). Similarly flammability analysis has been performed to investigate fire behavior of polystyrene (PS), polyethylene terephthalate (PET), polypropylene (PP) and polyvinyl chloride (PVC) (Shi et al., 2013). Fire behaviors of polycarbonates (PC) and polyvinyl chloride (PVC) have been investigated (Stoliarov et al., 2010). They have demonstrated the relation among cone calorimeter results with model equations using a computational framework called ThermaKin (Lyon and Stoliarov, 2009; Stoliarov, 2010). Generalized pyrolysis model for combustible solids using Gpyro model for polymethyl methacrylate (PMMA) and polyurethane foam have been developed (Lautenberger and Fernandez-Pello, 2009). Most of this research has yielded a general idea about how a polymer degrades under pyrolysis conditions, what are the different stages involved and the external factors governing the process. Thus a sound qualitative interpretation has been developed with an insight that the fire behavior can be modeled and hence quantified. As such pyrolysis models have been reviewed by and published (Di Blasi, 1993; Kashiwagi, 1994; Fernandez-Pello, 1995; Moghtaderi, 2006; Fernandez-Pello and Lautenberger, 2008). Current research work is an effort to bridge this gap and create a platform for quantitative comparison of polymer fire behavior.

Enhancing the fire behavior of polymer means to reduce the generation of smoke and noxious gases, to prevent the entire polymer from getting burnt and increase the time until when polymer 
retains its mechanical strength so as to allow effective egress time in case of emergency fire scenarios. This calls for a quantitative understanding of the polymer fire behavior. This paper talks about the flammability analysis of pure polymer (PE) using cone calorimeter and validating a set of mathematical models to predict the polymer thermal inertia, critical heat flux and peak heat release rate. To conclude the paper, external heat flux and HRR have been correlated with thermal inertia of PE and exhaust gas composition resulting in quantitative interpretation of PE thermal degradation.

\section{Experimental}

\subsection{Material Specimen}

Material used for this study was white non-charring Polyethylene (PE), supplied by SIGMAALDRICH. Being a laboratory grade polymer, it was assumed that sample contains negligible quantities of chlorine and sulfur impurities. Its molecular weight and molecular weight distribution were obtained using Gel Permeation Chromatography (GPC) (Sigma Aldrich Safety datasheet, 2014). PE employed in this work was in form of small granules with an average particle size of $1 \mathrm{~mm}$. Number average molecular weight (Mn) for the sample is $7700 \mathrm{~g} \cdot \mathrm{mol}^{-1}$ and molecular weight is $35000 \mathrm{~g} \cdot \mathrm{mol}^{-1}$ with melt index of 2,250 $\mathrm{g} \cdot(10 \mathrm{~min})^{-1}$. Polymers being employed in construction industry as support structures, separators, moisture containment and in other applications have density of $0.92-0.94 \mathrm{~g} \cdot \mathrm{cm}^{-3}$, which corresponds to molecular weight of the order of $>10000 \mathrm{~g} \cdot \mathrm{mol}^{-1}$. Thus, polyethylene with molecular weight of $35000 \mathrm{~g} \cdot \mathrm{mol}^{-1}$ was selected for the current study.

\subsection{Cone Calorimeter}

Cone calorimeter is a sophisticated and a significant bench scale instrument employed to conduct flammability analysis of PE. Cone calorimeter has been accepted by the International Organization for Standardization (ISO) 5660-1 for measuring heat release rate of a sample (ISO 5660-1, 2002). It has been observed and recorded in the literature that approximately 13.1 MJ of heat is liberated per unit kg of oxygen consumed in the combustion reaction. Thus based on the observed consumption of oxygen we can determine the amount of heat released for a sample under consideration. The instrument used for the current work is supplied by Fire Testing 
Technology Limited. Following were some of the important calibration parameters of cone calorimeter for current work in line with standard recommended practice by Fire Testing Technology Limited:
a. $\quad$ Ambient pressure $=97.688 \mathrm{kPa}$
b. Ambient temperature $=24^{\circ} \mathrm{C}$
c. Relative humidity $=63 \%$
d. Exhaust duct volumetric flow rate $=24 \pm 31 \cdot \mathrm{s}^{-1}=0.024 \pm 0.003 \mathrm{~m}^{3} \cdot \mathrm{s}^{-1}$
e. Baseline oxygen concentration $=20.95 \%(\mathrm{v} / \mathrm{v})$
f. Baseline carbon dioxide concentration $=0.067 \%(\mathrm{v} / \mathrm{v})$
g. Incident heat flux from cone heater (four tests) $=40,45,50,55 \mathrm{~kW} \cdot \mathrm{m}^{-2}$
h. Surface area exposed to the incident heat flux $=88.36 \mathrm{~cm}^{2}$

\subsection{Sample Preparation}

As the polyethylene sample was in granule form, it was precisely weighed into 12 equal samples of 25 gm each with an accuracy of $\pm 0.1 \mathrm{gm}$. The temporary sample holder was created using aluminum foil. The sample was evenly spread through the sample holder having dimensions 100 $\mathrm{x} 100 \mathrm{~mm} \pm 1 \mathrm{~mm}^{2}$. Though the surface area exposed to incident heat flux is limited to $94 \times 94 \mathrm{~mm}^{2}$, due to use of edge lip sample holder frame. Thickness of the sample for all the tests was maintained uniformly as $5 \mathrm{~mm}$. A practical spectrum of heat fluxes was employed ranging from $40 \mathrm{~kW} \cdot \mathrm{m}^{-2}$ to $55 \mathrm{~kW} \cdot \mathrm{m}^{-2}$ in step of $5 \mathrm{~kW} \cdot \mathrm{m}^{-2}$. Heat flux range was selected so as to make each test last over duration of $10-15$ min, allowing sufficient time to record the data and properly spread profiles to identify different regions of polymer degradation. Three sets of tests were performed at each heat flux.

All polymer samples were mounted horizontally, using a specimen holder with edge frame. The bottom of the specimen holder was supported with two layers of insulating material with effective thickness of $30 \mathrm{~mm}$. Each specimen was allowed to attain its autoignition temperature before getting ignited. No external ignition source or pilot flame was employed during the experiments. Following Figure $1, a, b, c, d, e, f, g, h, i, j, k, l$ and $m$ exhibit various stages of sample preparation and instances captured during a cone test. Also, the final remains obtained at the end of the test are demonstrated in part $l$ and $m$. 


\subsection{Data Collection}

Various events were recorded during the timeline of each test such as start of test, ignition time, flame out time and end of test time. Here, start of tests corresponds to the instance when sample is first exposed to external heat flux. Ignition time corresponds to the instance when sample starts burning. Flame out time corresponds to the instance when the flame is almost about to extinguish. And test stop time corresponds to the instance when the external heat flux is stopped. Table 1 shows observations for ignition time and flame out time for each test.

\section{Results and discussion}

\subsection{Thermal Inertia}

While studying the PE thermal degradation under autoignition condition (Shi and Chew, 2013), the only heat source available was cone. From the first principles of heat transfer (Rhodes et al., 1996; Hopkins Jr., 1996; Tewarson, 2002) following relations to relate external heat flux and ignition time with the basic properties of a polymer:

$$
\begin{aligned}
& \dot{q}_{e x t}=\frac{1}{s}\left[h_{c}\left(T_{i g}-T_{0}\right)+\varepsilon \sigma T_{i g}^{4}\right] \\
& t_{i g}=\frac{2}{3} k \rho C_{p}\left(\frac{T_{i g}-T_{0}}{\dot{q}_{\text {Ext }}}\right)^{2}
\end{aligned}
$$

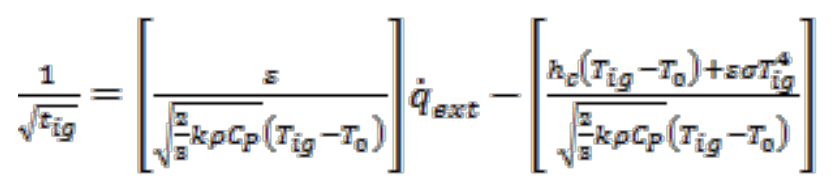

Here, $\dot{q}_{e x t}\left(\mathrm{~kW} \cdot \mathrm{m}^{-2}\right)$ is the set value of external heat flux being supplied by cone heater which remains constant through each test. $t_{i g}(\mathrm{sec})$ is the recorded ignition time during each test. $\varepsilon$ is the emissivity of PE which has a constant value of $\sim 0.92 . k\left(\mathrm{~kW} \cdot \mathrm{m}^{-1} \cdot \mathrm{K}^{-1}\right)$ is the thermal conductivity, $\rho\left(\mathrm{kg} \cdot \mathrm{m}^{-3}\right)$ is density and $C_{p}\left(\mathrm{~kJ} \cdot \mathrm{kg}^{-1} \cdot \mathrm{K}^{-1}\right)$ is specific heat of PE. Product of $k$, $\rho$ and $C_{p}$ is known as thermal inertia. $T_{i g}$ and $T_{0}$ are the absolute ignition temperature and absolute ambient temperature respectively. $h_{c}\left(\mathrm{~kW} \cdot \mathrm{m}^{-2} \cdot \mathrm{K}^{-1}\right)$ is the convective heat transfer coefficient 
among polymer surface and surrounding. $\sigma$ is Stefan Boltzmann constant which is $5.6704 \times 10^{-8} \mathrm{~W} \cdot \mathrm{m}^{-2} \cdot \mathrm{K}^{-4}$.

Equation 1 represents the external heat flux in terms of convective and radiative heat transfer. As there is no direct contact between sample and cone, conduction is not involved in the heat transfer. Thus, the resulting heat flux can be determined from combined effect of convective and radiative heat transfer. Equation 2 relates the ignition time of polymer sample to its thermal inertia and external heat flux determined from equation 1. Rearranging the equations 1 and 2 yields equation 3 which relates ignition time with external heat flux.

Comparing equation 3 with general equation of straight line, slope and intercept of the line can be expressed as equations 4 and 5 , respectively.

$$
\begin{gathered}
\text { Slope }=\frac{s}{\sqrt{\frac{\pi}{\mathrm{a}} k \rho C_{P}}\left(T_{i q}-T_{0}\right)} \\
y-\text { axis Intercept }=-\frac{h_{c}\left(T_{i g}-T_{0}\right)+\varepsilon \sigma T_{i q}^{4}}{\sqrt{\frac{z}{\mathrm{a}} k \rho C_{P}}\left(T_{i q}-T_{0}\right)}
\end{gathered}
$$

In this case, when we plot $t_{i g}^{-1 / 2}=f\left(\dot{q}_{\theta x t}\right)$, the slope of this straight line allows us to determine the different properties of PE such as thermal conductivity $(k)$, specific heat $\left(\mathrm{C}_{\mathrm{p}}\right)$ and Critical Heat Flux (CHF). Critical Heat Flux is defined as the minimum amount of heat flux required by a substance to auto-ignite. For any given substance if the applied heat flux value is less than CHF, it will not ignite.

$$
\text { CHF }=-\frac{y_{\text {intercept }}}{\text { slope }}
$$

Figure 2 shows the profile of graph obtained when the square root of the inverse of ignition time is plotted against external irradiance along with the error bars in ignition time recorded. It is observed that it represents a linear relation as depicted in Equation 3. When a straight line is drawn to fit the data, observed slope $=3.41 \times 10^{-3}$ and y-intercept $=-2.33 \times 10^{-2}$. From the observed values of slope and intercept the thermal inertia for PE can be determined. The same were then validated using correlations (van Krevelen and te Nijenhuis, 2009; Orwoll and Flory, 1967; Vasile and Pascu, 2005) for PE over the temperature range from room temperature to its 
autoignition temperature. It was observed that the properties predicted both from the graph and the correlations turned out to be in good agreement. Difference among the values was found to be $\pm 3.49 \%$.

\subsection{Critical Heat Flux}

Critical heat flux for PE can be determined if we observe the point where the straight line intersects $\mathrm{X}$-axis in Figure 2. The intersection point gives the critical heat flux for PE as $\sim 7 \mathrm{~kW} \cdot \mathrm{m}^{-2}$. This value is not the actual critical heat flux for PE. Practical value of critical heat flux for PE is on higher side of what is being inferred from Figure 2. To determine the realistic value for critical heat flux, the integral analysis model for ignition was employed (Shi and Chew, 2013; Spearpoint and Quintiere, 2000-01). The model is based on following assumptions has been used, which also hold true for current experimental system:

- Polymer sample ignites only when its surface temperature attains a critical value of autoignition temperature.

- Solid polymer sample act as an inert until ignition

- Solid is infinitely thick (to justify the boundary condition)

$$
\begin{aligned}
& \frac{1}{\sqrt{\pi_{i g}}}=\left[\frac{2\left(2-\beta_{i g}\right)\left(1-\beta_{i g}\right)}{\pi}\right]^{1 / 2} \frac{1}{\beta_{i g}} \\
& \frac{1}{\sqrt{\pi_{i g}}}=\frac{2}{\sqrt{\pi}}\left(\frac{1}{\beta_{i g}}-0.64\right) ; \frac{1}{\beta_{i g}}>3 \\
& \frac{1}{\sqrt{\pi_{i g}}}=\sqrt{\pi}\left(\frac{1}{\beta_{i g}}-1\right) ; \frac{1}{\beta_{i g}}<1.1
\end{aligned}
$$

Here,

$$
\begin{gathered}
\tau_{i g}=\frac{\dot{q}_{E x t}^{2} t_{i g}}{\left(T_{i q}-T_{0}\right)^{2} k \rho C_{P}} \\
\beta_{i g} \equiv \frac{\sigma\left(T_{s}^{4}-T_{0}^{4}\right)+h_{i}\left(T_{s}-T_{0}\right)}{\dot{q}_{e x t}} \equiv \frac{\dot{q}_{C r t}}{\dot{q}_{\mathrm{Ext}}}
\end{gathered}
$$

Equation 7 represents the integral analysis model developed by Quintiere (Spearpoint and Quintiere, 2000, 2001). Equations 8 and 9 respectively are the special cases of equation 7 developed by Delichatsios (Delichatsios et al., 1991); wherein the original model has been 
divided into two distinct equations based on the values of $1 / \beta_{i g}$ corresponding to high and low heat fluxes. Here $\tau_{i g}$ is the dimensionless ignition time which is defined as mentioned in equation $10 . \beta_{i g}$ is the dimensionless ratio of convective and radiative loss to the incident heat flux, as expressed in equation 11.

On plotting the points of $\frac{1}{\sqrt{r_{i g}}}$ vs. $\frac{1}{\beta_{i g}}$ based on equations 7,8 and 9 following profiles are obtained as shown in figure 3.

Now from the integral model solution for equation 7, choosing three distinct values for heat flux yields,

$$
\begin{aligned}
& \frac{1}{\sqrt{\tau_{i g}}}=1.38 \text { when } \frac{1}{\beta_{i g}}=2.0 \\
& \frac{1}{\sqrt{\tau_{i g}}}=3.09 \text { when } \frac{1}{\beta_{i g}}=3.5 \\
& \frac{1}{\sqrt{\tau_{i g}}}=4.78 \text { when } \frac{1}{\beta_{i g}}=5.0
\end{aligned}
$$

At high heat fluxes, $\beta_{i g} \ddagger 0$, so equation 7 can be rewritten as

$$
\frac{1}{\sqrt{r_{i g}}}=\frac{2}{\sqrt{\pi}}\left(\frac{1}{\beta_{i g}}\right)
$$

Further the difference between the exact solution and the extrapolated solution is $\left(1 / \beta_{i g}-1 / \beta_{\text {ig.intercept }}\right)$. Thus equation 12 can be written as

$$
\frac{1}{\sqrt{\tau_{i g}}}=\frac{2}{\sqrt{\pi}}\left(\frac{1}{\beta_{i g}}-\frac{1}{\beta_{\text {ig intercept }}}\right)
$$

Now, substituting the values for $\frac{1}{\sqrt{r_{i g}}}$ and $\frac{1}{\beta_{i g}}$ the respective values for $\frac{1}{\beta_{i g, \text { int }}}$ obtained are 0.78 , 0.76 and 0.76 . Taking average of these values yields a factor of 0.77 . Plug this value along with the value for the $\mathrm{X}$-axis intercept value obtained from Figure 3, in equation 11 to get the actual critical heat flux for PE. 


$$
\dot{q}_{\text {crt }}=\frac{\dot{q}_{\text {int }}}{0.77}
$$

Similarly, Delichatsios (Delichatsios et al., 1991) proposed the factor value to be 0.64 based on their high heat flux model described in equation 8.

The values of critical heat flux determined are $\sim 9.09 \mathrm{~kW} \cdot \mathrm{m}^{-2}$ for the Quintiere model and $\sim 10.93 \mathrm{~kW} \cdot \mathrm{m}^{-2}$ for the Delichatsios model. There is a wide range of reported values of critical heat flux for polyethylene available in literature ranging between $10-25 \mathrm{~kW} \cdot \mathrm{m}^{-2}$ (Hopkins $\mathrm{Jr}$., 1995).

\subsection{Heat Release Rate (HRR)}

For a fire to occur three basic things required are the fuel source, sufficient oxygen supply, an ignition source and sustained chain reactions. Whereas for a fire to propagate, a potential source for heat emission is required to sustain the flame in absence of ignition source. Thus, heat release rate becomes one of the important aspects to be considered while studying the fire retardancy of polymers (Babrauskas and Peacock, 1992; Babrauskas, 2003). The rate of heat release ultimately controls the spread of fire, generation of noxious gases and smoke. Current work determined the heat release rate based on the concentrations of various gaseous species such as $\mathrm{O}_{2}, \mathrm{CO}, \mathrm{CO}_{2}$ and $\mathrm{H}_{2} \mathrm{O}$ in the ambient air as well as in the exhaust gas as they comprise of more than 99\% v/v of the gases. Oxygen depletion factor is calculated based on the change in mole fraction of gaseous species in the ambient air and exhaust gas as expressed in equation 15 which is approved by ISO 5660-1 (ISO 5660-1, 2002). Equation 15 represents the oxygen depletion factor ( $\varphi$ ) (Janssens, 1991; Enright, 1999).

$$
\begin{aligned}
& \varphi=\frac{x_{O_{2}}^{0}\left(1-X_{C O}-X_{C_{2}}\right)-X_{O_{2}}\left(1-X_{C O_{2}}^{0}\right)}{x_{O_{2}}^{0}\left(1-X_{O_{2}}-X_{C O_{2}}-x_{C O}\right)} \\
& H R R=\frac{1}{A}\left\{E \varphi-\left(E_{C O}-E\right) \frac{1-\varphi}{2} \frac{X_{C O}}{x_{O_{2}}}\right\} \frac{M_{O_{2}}}{M_{\text {Air }}} \dot{m}_{A i r}\left(1-X_{H_{2} O}^{0}-X_{C O_{2}}^{0}\right) X_{O_{2}}^{0} \\
& \frac{\tilde{m}_{\text {Air }}}{M_{\text {Air }}}=\frac{\left(1-X_{H_{2} O}\right)\left(1-X_{O_{2}}-X_{C_{2}}-X_{C O}\right)}{\left(1-x_{H_{2} O}^{0}\right)\left(1-x_{O_{2}}^{0}-x_{C_{2}}^{0}\right)} \frac{\tilde{m}_{e}}{M_{e}}
\end{aligned}
$$


Here, $E$ represents net heat release per unit mass of oxygen consumed and is equal to 13.1 $\mathrm{MJ} \cdot \mathrm{kg}^{-1}$ of $\mathrm{O}_{2}$. Similarly $E_{\text {Co }}$ is heat release per unit mass of oxygen consumed to produce CO which is equal to $17.6 \mathrm{MJ} \cdot \mathrm{kg}^{-1}$ of $\mathrm{O}_{2}$. Further $\mathrm{A}=88.36 \mathrm{~cm}^{2}$ is the area of the polymer sample exposed to the external heat flux from cone heater, molecular weight of oxygen $\left(M_{O_{2}}\right)=32$ $\mathrm{g} \cdot \mathrm{mol}^{-1}$, molecular weight of air $\left(M_{\text {Air }}\right)=28.8 \mathrm{~g} \cdot \mathrm{mol}^{-1}$, mass flow rate of air $\left(\dot{m}_{\text {Air }}\right), X_{i}^{0}$ is the initial mole fraction of gaseous species $i$ in exhaust duct before the test has started and $X_{i}$ is the mole fraction of the gaseous species $i$ in the exhaust duct over the duration of test. Here subscript $i$ is $\mathrm{O}_{2}, \mathrm{CO}, \mathrm{CO}_{2}$ and $\mathrm{H}_{2} \mathrm{O}$. Further to simplify the calculations a reasonable assumption was made that the gas flowing through the exhaust duct is same in composition to the air, as there are only small change in concentrations of gaseous species. Thus, concluding that the molecular weight of exhaust gas is same as that of ambient air $\left(\sim 28.8 \mathrm{~g} \cdot \mathrm{mol}^{-1}\right)$.

From the experiments performed for heat fluxes ranging from $40-55 \mathrm{~kW} \cdot \mathrm{m}^{-2}$, peak heat release rates have been recorded for each case and equation 16 facilitates calculation of peak heat release rate. Tables 2-4 represent the observed concentrations of the oxygen, carbon monoxide, carbon dioxide and moisture in the ambient air and exhaust gas. Further tables 5-8 give comparison among the observed and calculated peak heat release rates.

To determine the peak heat release rate the concentration for the gaseous fractions corresponding to the time of peak heat release rate, obtained from their respective exhaust gas concentration profiles were used. Heat release rate profiles for all the tests are shown in Figure 4. Exhaust gas concentration profiles for oxygen, carbon monoxide and carbon dioxide are represented in Figures 5, 6 and 7.

A deviation from the standard practice to determine the concentration of moisture in exhaust gas was exercised as the experimental set up did not have the facility to observe and record the concentration of moisture in the exhaust gas. Instead relative humidity in ambient air was recorded at the beginning of each test which facilitated determination of $\% \mathrm{H}_{2} \mathrm{O}$ in the ambient air using its saturation vapor pressure at ambient temperature. Further to that combustion reaction is the only source available for concentration of $\mathrm{H}_{2} \mathrm{O}$ to change in exhaust gas. Hence, based on the \% change in concentration of carbon monoxide \& carbon dioxide and the stoichiometric coefficients of combustion reactions, \% concentration of $\mathrm{H}_{2} \mathrm{O}$ in the exhaust gas stream was estimated. 
The above mentioned process resulted in standard deviation of $\pm 4.56 \%$ among observed and calculated values of peak heat release rate, which is acceptable as per the literature data available.

\section{Conclusion}

From flammability analysis of polyethylene it can be concluded that increase in external heat flux results in increased peak heat release rate, early ignition and rapid thermal degradation. As the external heat flux increases it has been observed that oxygen consumption also increases validating the higher heat release rate. With increase in external heat flux the concentrations of carbon monoxide and carbon dioxide in the exhaust gas increases considerably. Based on the heat release rate profile, thermal degradation of polyethylene can be classified into four distinct regimes corresponding to physical degradation, ignition \& flame development, flame stabilization and flame out. With the proposed model equations being validated for the thermal inertia and peak heat release rate for polyethylene, it can be concluded that a strong platform has been created towards quantification of polyethylene fire behavior. Current work is an effort to bridge the gap among the qualitative understanding of polymer fire behavior and the quantitative insight of adding dopant into the polymer to enhance its fire retardancy. This research validated that quantitative models can predict the polymer fire behavior and will play a vital role in the study of tailor made fire retardant polymers in the future. The applications of the validated models to fire retardant polymers are currently underway.

\section{Acknowledgement}

Authors are thankful to National Science Foundation (NSF) for their financial support for the research project (CBET-1336254 and CBET-1336162). 


\section{Nomenclature}

$$
\begin{aligned}
& \dot{q}_{\text {ext }} \quad=\text { external heat flux }\left(\mathrm{kW} \cdot \mathrm{m}^{-2}\right) \\
& \dot{q}_{\text {crt }} \quad=\text { critical heat flux }\left(\mathrm{kW} \cdot \mathrm{m}^{-2}\right) \\
& E \quad=\text { emissivity (dimensionless) } \\
& h_{c} \quad=\text { convective heat transfer coefficient }\left(\mathrm{kW} \cdot \mathrm{m}^{-2} \cdot \mathrm{K}^{-1}\right) \\
& T_{i g} \quad=\text { ignition temperature (K) } \\
& T_{0} \quad=\text { ambient (initial) temperature (K) } \\
& \sigma \quad=\text { Stephan-Boltzmann constant }\left(5.6704 \times 10^{-8} \mathrm{~W} \cdot \mathrm{m}^{-2} \cdot \mathrm{K}^{-4}\right) \\
& t_{i g} \quad=\text { ignition time (sec) } \\
& \tau_{i g} \quad=\text { dimensionless time (dimensionless) } \\
& k \quad=\text { thermal conductivity }\left(\mathrm{kW} \cdot \mathrm{m}^{-1} \cdot \mathrm{K}^{-1}\right) \\
& \rho \quad=\text { density }\left(\mathrm{kg} \cdot \mathrm{m}^{-3}\right) \\
& C_{p} \quad=\text { specific heat }\left(\mathrm{kJ} \cdot \mathrm{kg}^{-1} \cdot \mathrm{K}^{-1}\right) \\
& \beta_{i g} \quad=\text { ratio of convective gain and radiative loss with incident heat flux (dimensionless) } \\
& \varphi \quad=\text { oxygen depletion index (dimensionless) } \\
& X_{i}^{0} \quad=\text { initial mole fraction of gaseous species } i \text { in the exhaust duct before test }
\end{aligned}
$$$$
\text { Here, } i=\mathrm{O}_{2}, \mathrm{CO}_{2}, \mathrm{CO}, \mathrm{H}_{2} \mathrm{O}
$$$$
X_{i} \quad=\text { mole fraction of gaseous species } i \text { in the exhaust gas during the course of test }
$$$$
\text { Here, } i=\mathrm{O}_{2}, \mathrm{CO}_{2}, \mathrm{CO}, \mathrm{H}_{2} \mathrm{O}
$$$$
\dot{m}_{\tilde{i}} \quad=\text { mass flow rate of species } i \text {, here } i=\text { Air, exhaust gas }(\sim \mathrm{e})
$$$$
M_{i} \quad=\text { molecular weight of gaseous species } i \text {, here } i=\text { Air, } \mathrm{O}_{2} \text {, exhaust gas ( e) }
$$ 


\section{References}

Babrauskas, V., 2003. Ignition Handbook. Fire Sciences Publishers.

Babrauskas, V., Peacock, R.D., 1992. Heat release rate: The single most important variable in fire hazard. Fire Saf. J. 18, 255-272.

Babrauskas, V., Grayson, G., 1992. Heat release in fires. Essex, England: Elsevier Science Publishers Ltd.

Delichatsios, M.A., Panagiotou, T., Kiley, F., 1991. The use of time to ignition data for characterizing the thermal inertia and the minimum (critical) heat flux for ignition or pyrolysis. Combust. Flame. 84, 323-332.

Di Blasi, C., 1993. Modeling and simulation of combustion processes of charring and non-charring solid fuels. Prog. Energ. Combust. 19, 71-104.

Enright, P.A., 1999. Heat release and combustion behaviour of upholstered furniture. University of Canterbury.

Fernandez-Pello, A.C., 1995. The solid phase, in: Combustion Fundamentals of Fire. Academic Press.

Fernandez-Pello, A.C., Lautenberger, C., 2008. Pyrolysis modeling, thermal decomposition and transport processes in combustible solids, in: Transport phenomena in fires. WIT Press.

Hopkins Jr., D., Quintiere J.G., 1996. Material fire properties and predictions for thermoplastics. Fire Saf. J. 26, 241-268.

Hopkins Jr., D., 1995. Predicting the ignition time and burning rate of thermoplastics in the cone calorimeter. University of Maryland.

Huggett, C., 1980. Estimation of rate of heat release by means of oxygen consumption measurements. Fire Mater. 4, 61-65.

International Organization of Standardization (ISO) 5660, 2002. Reaction to fire tests - heat release, smoke production and mass loss rate - Part 1 Heat release rate (cone calorimeter method).

Janssens, M., 1991. Measuring rate of heat release by oxygen consumption. Fire Technol. 27, 234-249.

Janssens, M., 2002. SFPE Handbook of fier Protection Engineering. NFPA.

Kashiwagi, T., 1994. Polymer combustion and flammability - role of the condensed phase. in 25th Combustion Institute Symposium (International) on Combustion.

Lautenberger, C., Fernandez-Pello, C., 2009. Generalized pyrolysis model for combustible solids. Fire Saf. J. 44, 819-839.

Luche, J., Rogaume, T., Richard, F., Guillaume, E., 2011. Characterization of thermal properties and analysis of combustion behavior of PMMA in a cone calorimeter. Fire Saf. J. 46, 451-461. 
Lyon, R.E., Stoliarov, S.I., 2009. Thermo-Kinetic model of burning for pyrolyzing materials. in Ninth International Symposium on fire Safety Science.

Moghtaderi, B., 2006. The state-of-the-art in pyrolysis modeling of lignocellulosic solid fuels. Fire Mater. 30, 1-34.

Orwoll, R.A., Flory, P.J., 1967. Equation- of-state parameters for normal alkanes. Correlation with chain length. J. Am. Chem. Soc. 89, 6814-6822.

Rhodes, B.T., Quintiere, J.G., 1996. Burning rate and flame heat flux for PMMA in a cone calorimeter. Fire Saf. J. 26, 221-240.

Safety Data Sheet for Polyethylene. 2014. Sigma-Aldrich.

Shi, L., Chew, M.Y.L., 2013. Fire behaviors of polymers under autoignition conditions in a cone calorimeter. Fire Saf. J. 61, 243-253.

Spearpoint, M.J., Quintiere, J.G., 2001. Predicting the piloted ignition of wood in the cone calorimeter using an integral model - effect of species, grain orientation and heat flux. Fire Saf. J. 36, 391415.

Spearpoint, M.J., Quintiere, J.G., 2000. Predicting the burning of wood using an integral model. Combust. Flame 123, 308-325.

Stoliarov, S.I., Crowley, S., Walters, R.N., Lyon, R.E., 2010. Prediction of the burning rates of charring polymers. Combust. Flame 157, 2024-2034.

Tewarson, A., 2002. Generation of heat and chemical compounds in fires. 3rd ed., Quincy, MA: The National Fire Protection Association Press. (chapter 4, section 3)

Thornton, W., 1917. The relation of oxygen th the heat of combustion of organic compounds. Philos. Mag. J. Sci. 33, 196-203.

van Krevelen, D.W., te Nijenhuis, K., 2009. Properties of polymers, Their correlation with chemical structure; their numerical estimation and prediction from additive group contributions. 4th ed., Elsevier.

Vasile, C., Pascu, M., 2005. Practical guide to polyethylene. Rapra Technology Limited.

Wang, Q., 2013. Polymer nanocomposite: A promising flame retardant. J. Mater. Sci. Nanotechnol. 1(2): e202. 

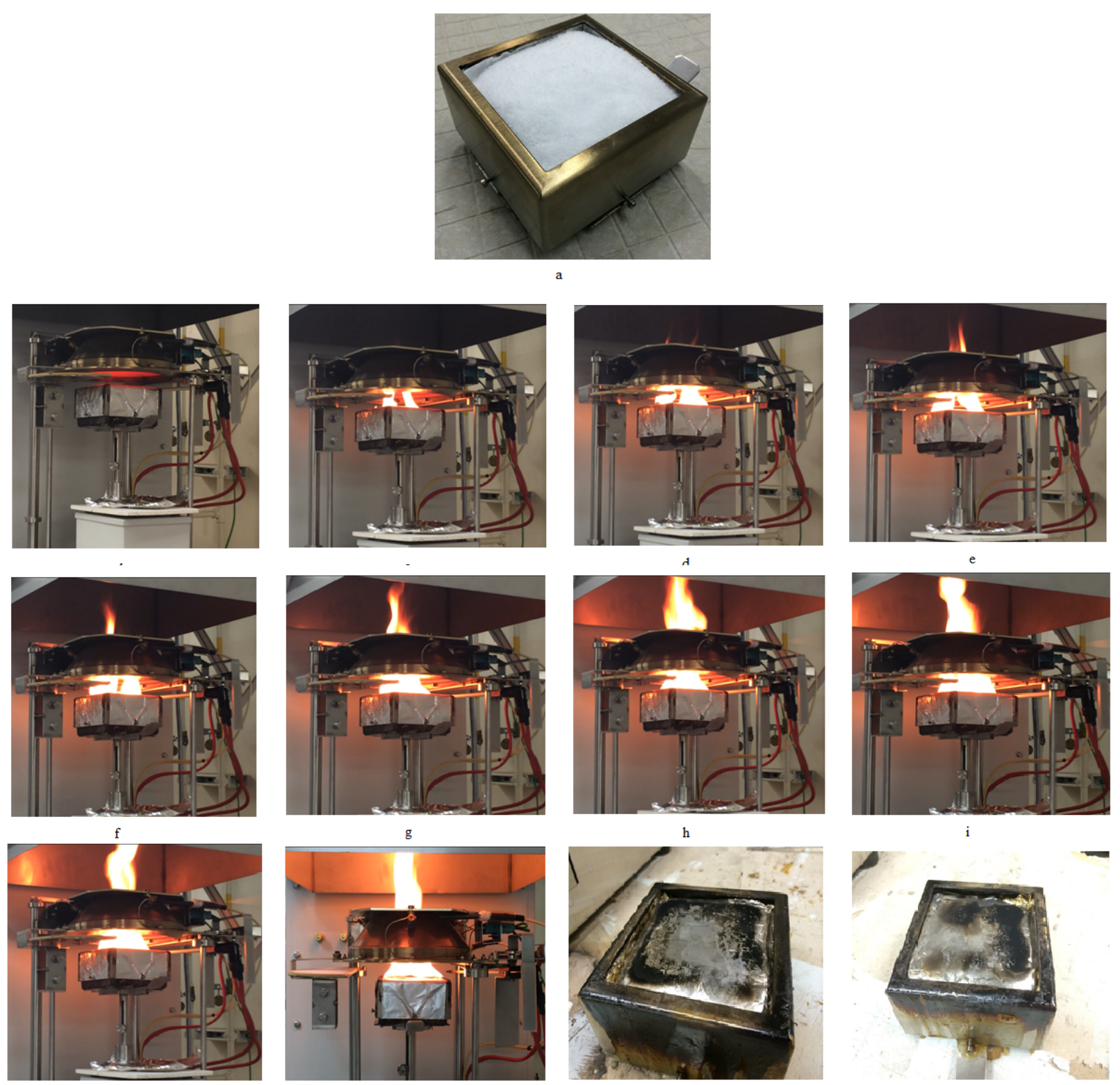

Figure 1 Sample preparation and test snapshots 


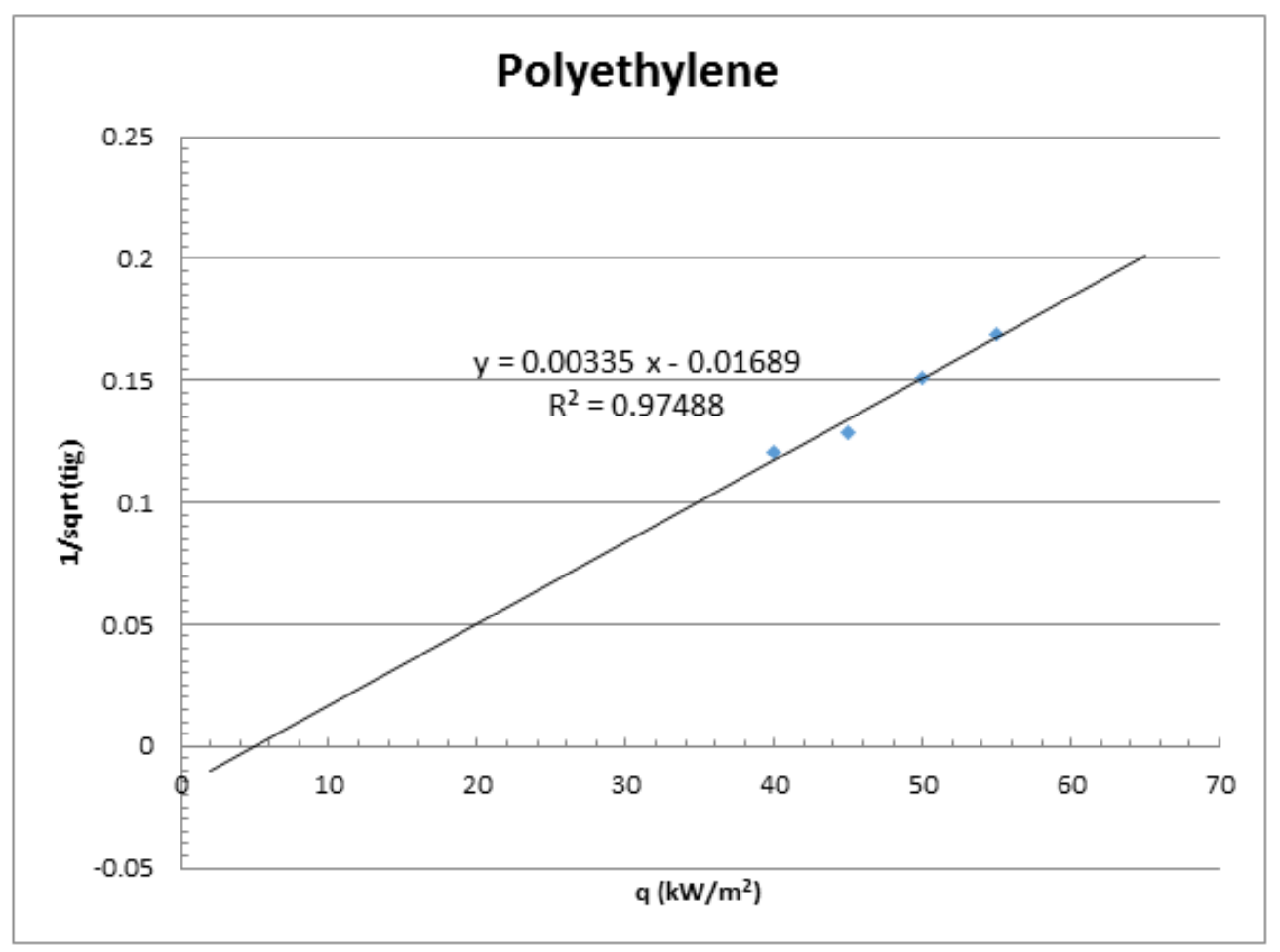

Figure 2 Ignition time vs. external heat flux for polyethylene

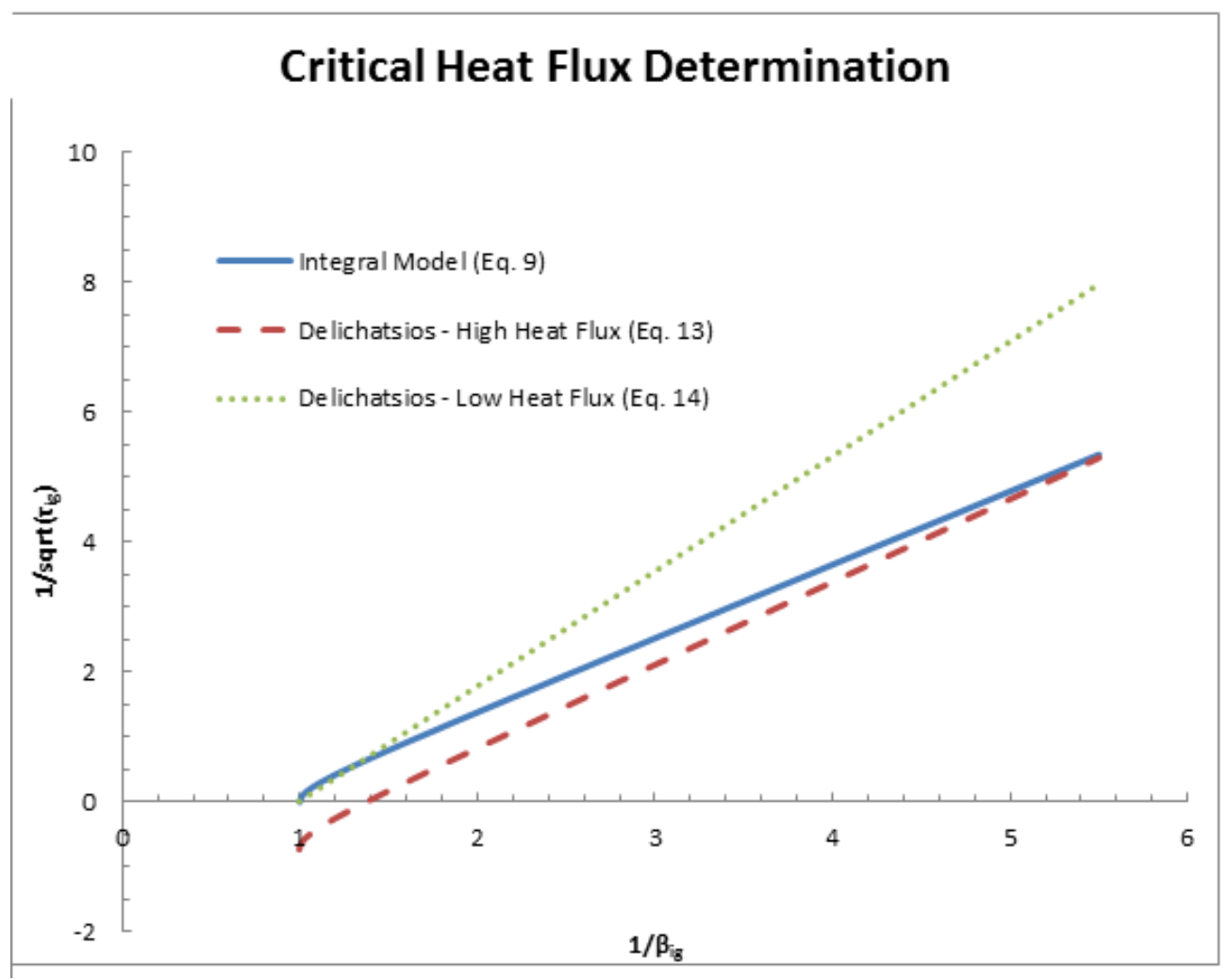

Figure 3 Comparison of integral model vs. Delichatsios model 


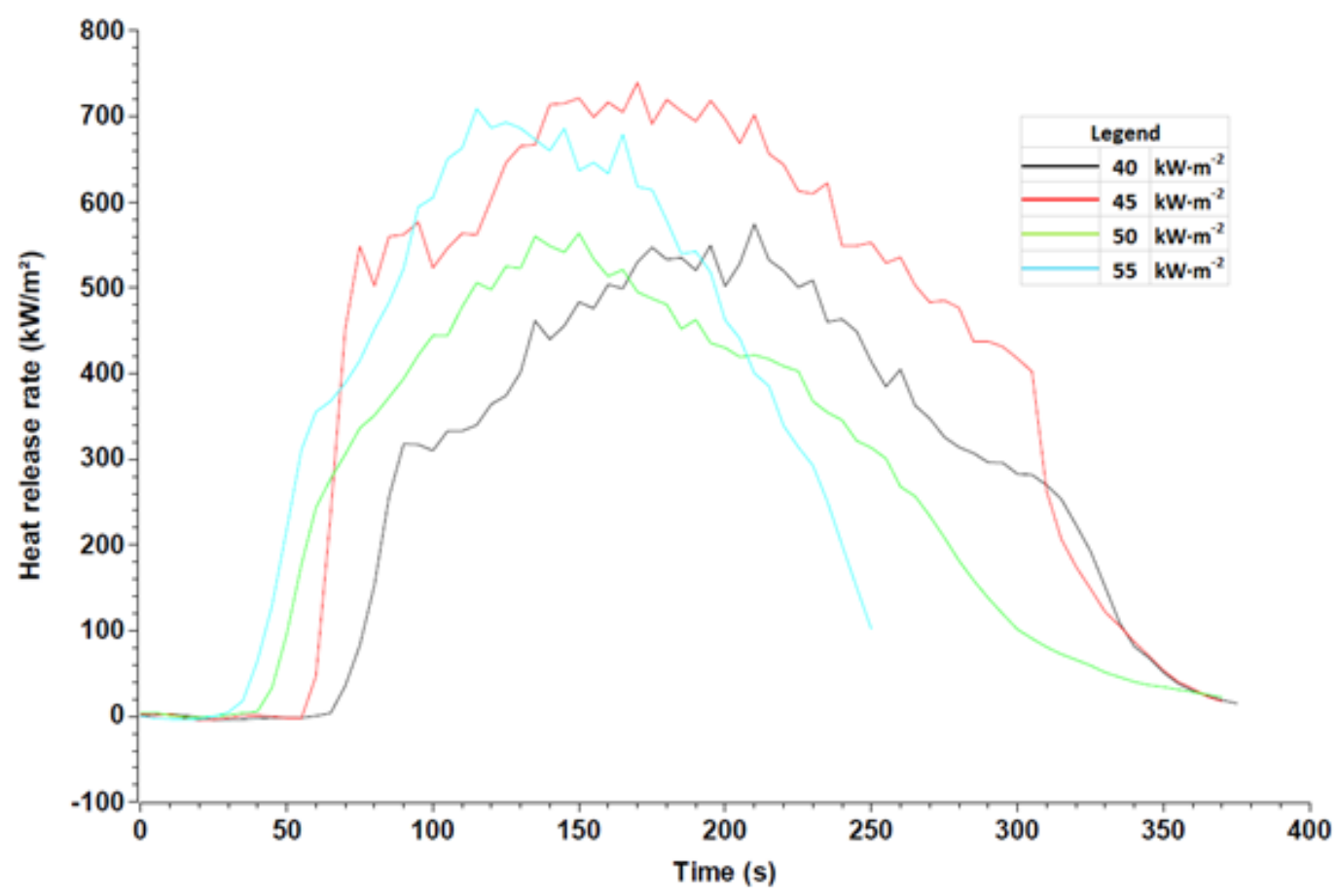

Figure 4 Heat release profiles

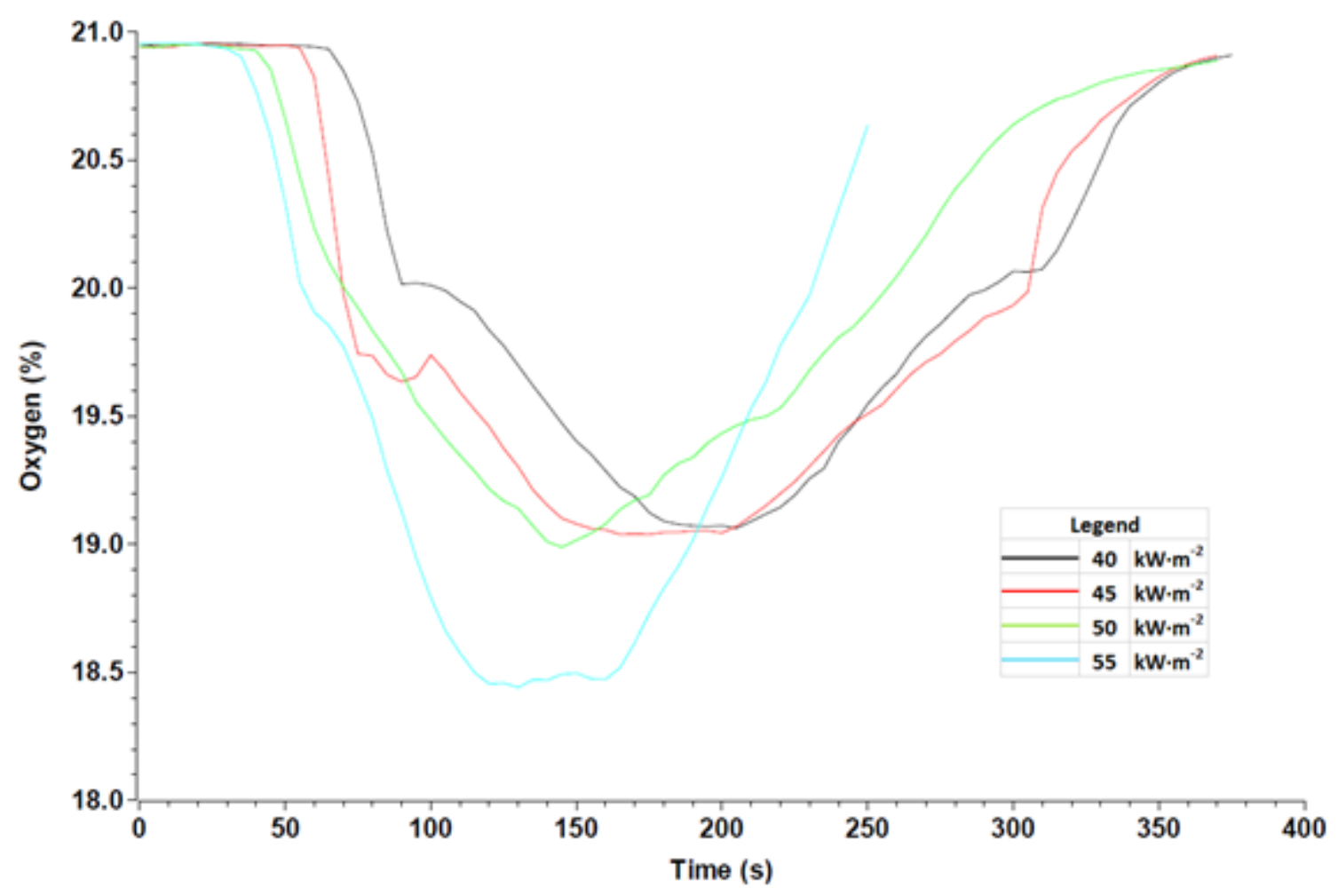

Figure 5 Oxygen concentration profile in exhaust gas 


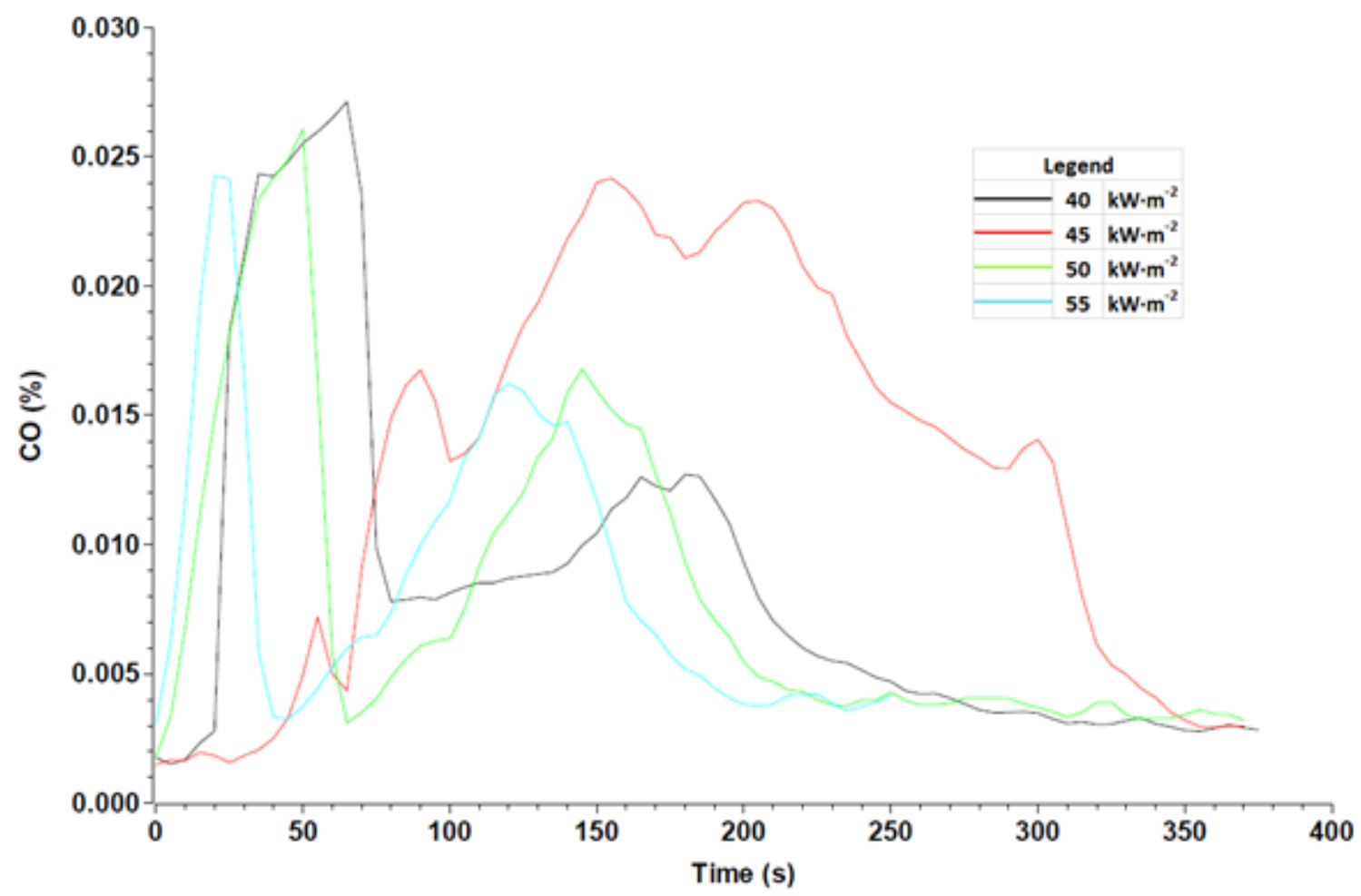

Figure 6 Carbon monoxide concentration profile in exhaust gas

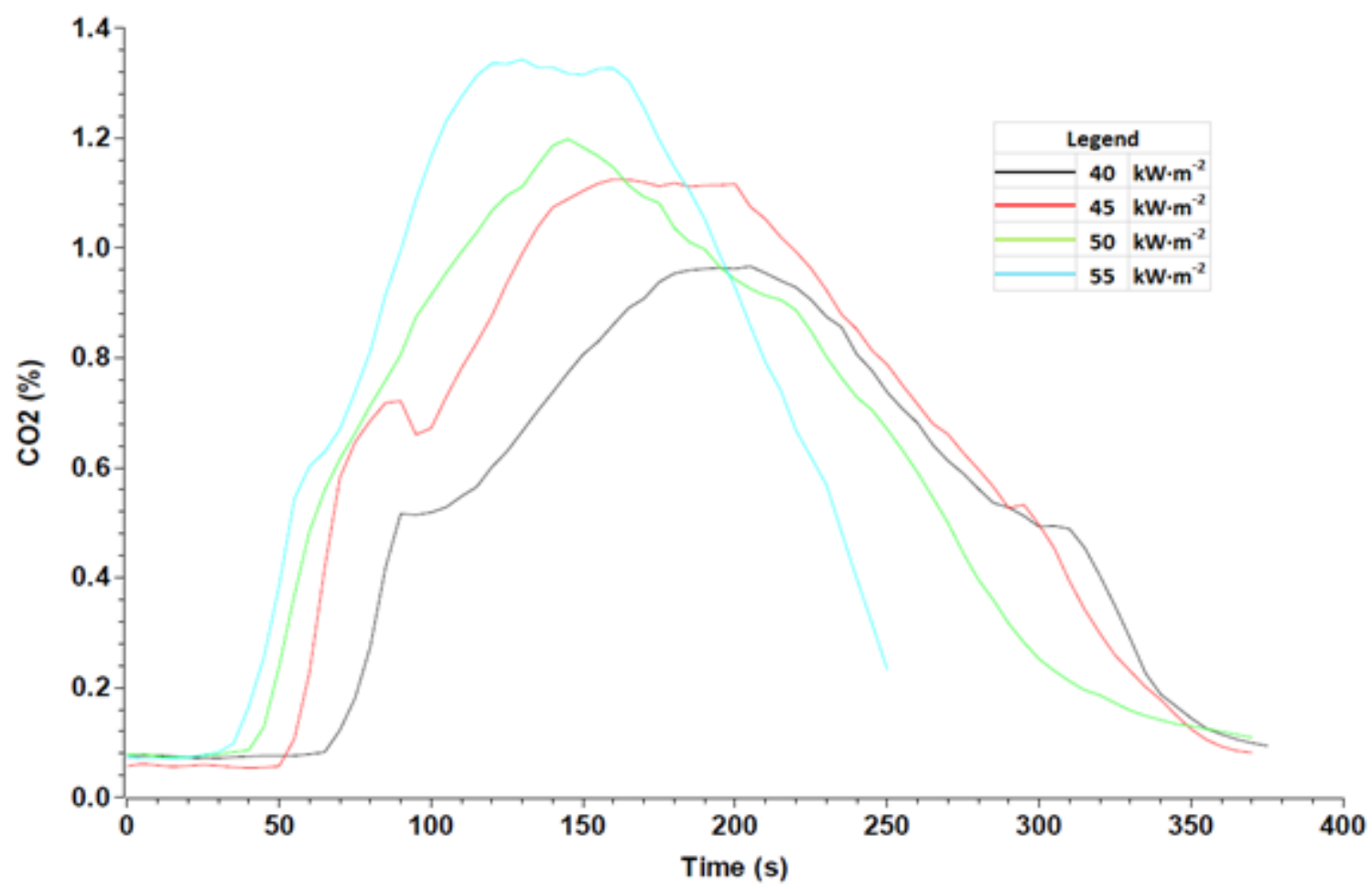

Figure 7 Carbon dioxide concentration in exhaust gas 
Table 1 Timeline of test events

\begin{tabular}{|c|c|c|c|}
\hline $\begin{array}{l}\text { Test } \\
\text { No. }\end{array}$ & $\begin{array}{l}\text { Incident heat flux } \\
\qquad\left(\mathbf{k W} \cdot \mathbf{m}^{-2}\right)\end{array}$ & $\begin{array}{l}\text { Experimental average } \\
\text { ignition time (sec) }\end{array}$ & $\begin{array}{c}\text { Experimental average time to } \\
\text { flame out (sec) }\end{array}$ \\
\hline 1 & 40 & 72.3 & 421.3 \\
\hline 2 & 45 & 63.3 & 327.0 \\
\hline 3 & 50 & 48.3 & 321.7 \\
\hline 4 & 55 & 35.3 & 248.7 \\
\hline
\end{tabular}

Table 2 Concentrations of gas components in ambient air and exhaust gas (first set)

\begin{tabular}{|c|c|c|c|c|c|c|c|}
\hline $\begin{array}{c}\text { Heat Flux } \\
\left(\mathbf{k W} \cdot \mathbf{m}^{-2}\right)\end{array}$ & $\boldsymbol{X}_{\mathrm{O}_{2}}^{\mathbf{0}}$ & $\boldsymbol{X}_{\mathrm{CO}_{2}}^{\mathbf{0}}$ & $\boldsymbol{X}_{\mathrm{H}_{2} \mathrm{O}}^{\mathbf{O}}$ & $\boldsymbol{X}_{\mathrm{O}_{2}}$ & $\boldsymbol{X}_{\mathrm{CO}_{2}}$ & $\boldsymbol{X}_{\mathrm{CO}}$ & $\boldsymbol{X}_{\mathrm{H}_{2} \mathrm{O}}$ \\
\hline 40 & 0.2095 & $7.33 \times 10^{-4}$ & 0.0186 & 0.1908 & $9.60 \times 10^{-3}$ & $7.00 \times 10^{-5}$ & 0.0365 \\
\hline 45 & 0.2095 & $4.46 \times 10^{-4}$ & 0.006 & 0.1934 & $1.11 \times 10^{-2}$ & $2.36 \times 10^{-4}$ & 0.0329 \\
\hline 50 & 0.2095 & $7.18 \times 10^{-4}$ & 0.0189 & 0.19 & $1.18 \times 10^{-2}$ & $1.60 \times 10^{-4}$ & 0.0414 \\
\hline 55 & 0.2095 & $7.29 \times 10^{-4}$ & 0.0186 & 0.185 & $1.34 \times 10^{-2}$ & $1.32 \times 10^{-4}$ & 0.0439 \\
\hline
\end{tabular}

Table 3 Concentrations of gas components in ambient air and exhaust gas (second set)

\begin{tabular}{|c|c|c|c|c|c|c|c|}
\hline $\begin{array}{c}\text { Heat Flux } \\
\left(\mathbf{k W} \cdot \mathbf{m}^{-2}\right)\end{array}$ & $\boldsymbol{X}_{\boldsymbol{O}_{2}}^{\mathbf{0}}$ & $\boldsymbol{X}_{\mathrm{CO}_{2}}^{\mathbf{0}}$ & $\boldsymbol{X}_{\mathrm{H}_{2} \boldsymbol{O}}^{\mathbf{O}}$ & $\boldsymbol{X}_{\mathrm{O}_{2}}$ & $\boldsymbol{X}_{\mathrm{CO}_{2}}$ & $\boldsymbol{X}_{\mathrm{CO}}$ & $\boldsymbol{X}_{\mathrm{H}_{2} \boldsymbol{O}}$ \\
\hline 40 & 0.2095 & $4.36 \times 10^{-4}$ & 0.0066 & 0.1956 & $9.70 \times 10^{-3}$ & $1.8 \times 10^{-4}$ & 0.0255 \\
\hline 45 & 0.2095 & $4.68 \times 10^{-4}$ & 0.006 & 0.1886 & $1.43 \times 10^{-2}$ & $3.1 \times 10^{-4}$ & 0.0343 \\
\hline 50 & 0.2095 & $4.56 \times 10^{-4}$ & 0.006 & 0.189 & $1.40 \times 10^{-2}$ & $3.0 \times 10^{-4}$ & 0.0377 \\
\hline 55 & 0.2095 & $4.65 \times 10^{-4}$ & 0.006 & 0.177 & $2.20 \times 10^{-2}$ & $5.2 \times 10^{-4}$ & 0.0501 \\
\hline
\end{tabular}


Table 4 Concentrations of gas components in ambient air and exhaust gas (third set)

\begin{tabular}{|c|c|c|c|c|c|c|c|}
\hline $\begin{array}{c}\text { Heat Flux } \\
\left(\mathbf{k W} \cdot \mathbf{m}^{-2}\right)\end{array}$ & $\boldsymbol{X}_{\mathrm{O}_{2}}^{\mathbf{0}}$ & $\boldsymbol{X}_{\mathrm{Co}_{2}}^{\mathbf{0}}$ & $\boldsymbol{X}_{\mathrm{H}_{2} \mathrm{O}}^{\mathbf{O}}$ & $\boldsymbol{X}_{\mathrm{O}_{2}}$ & $\boldsymbol{X}_{\mathrm{CO}_{2}}$ & $\boldsymbol{X}_{\mathrm{Co}}$ & $\boldsymbol{X}_{\mathrm{H}_{2} \mathrm{O}}$ \\
\hline 40 & 0.2095 & $4.33 \times 10^{-4}$ & 0.0066 & 0.1958 & $9.40 \times 10^{-3}$ & $1.87 \times 10^{-4}$ & 0.0249 \\
\hline 45 & 0.2095 & $4.57 \times 10^{-4}$ & 0.006 & 0.186 & $1.58 \times 10^{-2}$ & $3.5 \times 10^{-4}$ & 0.0374 \\
\hline 50 & 0.2095 & $4.61 \times 10^{-4}$ & 0.006 & 0.1906 & $1.30 \times 10^{-2}$ & $2.65 \times 10^{-4}$ & 0.0316 \\
\hline 55 & 0.2095 & $4.67 \times 10^{-4}$ & 0.006 & 0.1785 & $2.14 \times 10^{-2}$ & $4.8 \times 10^{-4}$ & 0.0488 \\
\hline
\end{tabular}

Table 5 Peak heat release rate $\left(40 \mathrm{~kW} \cdot \mathrm{m}^{-2}\right)$

\begin{tabular}{|c|c|c|c|c|}
\hline Test & $\boldsymbol{\varphi}$ & $\mathbf{H R R}_{\exp } \mathbf{( k W \cdot \mathbf { m } ^ { - \mathbf { 2 } } )}$ & $\mathbf{H R R}_{\text {calc }}\left(\mathbf{k W} \cdot \mathbf{m}^{-\mathbf{2}}\right)$ & Error (\%) \\
\hline 1 & 0.1004 & 573.71 & 598.46 & 4.31 \\
\hline 2 & 0.0716 & 508.07 & 428.28 & 15.70 \\
\hline 3 & 0.0707 & 500.69 & 423.49 & 15.42 \\
\hline
\end{tabular}

Table 6 Peak heat release rate $\left(45 \mathrm{~kW} \cdot \mathrm{m}^{-2}\right)$

\begin{tabular}{|c|c|c|c|c|}
\hline Test & $\boldsymbol{\varphi}$ & $\mathbf{H R R}_{\mathbf{e x p}}\left(\mathbf{k W} \cdot \mathbf{m}^{-\mathbf{2}}\right)$ & $\mathbf{H R R}_{\text {calc }}\left(\mathbf{k W} \cdot \mathbf{m}^{-2}\right)$ & Error (\%) \\
\hline 1 & 0.0829 & 577.32 & 492.53 & 14.68 \\
\hline 2 & 0.1074 & 703.3 & 638.38 & 9.23 \\
\hline 3 & 0.1208 & 724.54 & 717.05 & 1.03 \\
\hline
\end{tabular}

Table 7 Peak heat release rate $\left(50 \mathrm{~kW} \cdot \mathrm{m}^{-2}\right)$

\begin{tabular}{|c|c|c|c|c|}
\hline Test & $\boldsymbol{\varphi}$ & $\mathbf{H R R}_{\exp }\left(\mathbf{k W} \cdot \mathbf{m}^{-\mathbf{2}}\right)$ & $\mathbf{H R R}_{\text {calc }}\left(\mathbf{k W} \cdot \mathbf{m}^{-\mathbf{2}}\right)$ & Error (\%) \\
\hline 1 & 0.1025 & 563.04 & 606.19 & 7.66 \\
\hline 2 & 0.1054 & 710.88 & 626.78 & 11.83 \\
\hline 3 & 0.0972 & 649.35 & 578.85 & 10.85 \\
\hline
\end{tabular}


Table 8 Peak heat release rate $\left(55 \mathrm{~kW} \cdot \mathrm{m}^{-2}\right)$

\begin{tabular}{|c|c|c|c|c|}
\hline Test & $\boldsymbol{\varphi}$ & $\mathbf{H R R}_{\exp }\left(\mathbf{k W} \cdot \mathbf{m}^{-\mathbf{2}}\right)$ & $\mathbf{H R R}_{\text {calc }}\left(\mathbf{k W} \cdot \mathbf{m}^{-\mathbf{2}}\right)$ & Error (\%) \\
\hline 1 & 0.1300 & 708.14 & 770.97 & 8.87 \\
\hline 2 & 0.1662 & 1010.71 & 975.79 & 3.45 \\
\hline 3 & 0.1582 & 1005.77 & 929.31 & 7.60 \\
\hline
\end{tabular}

